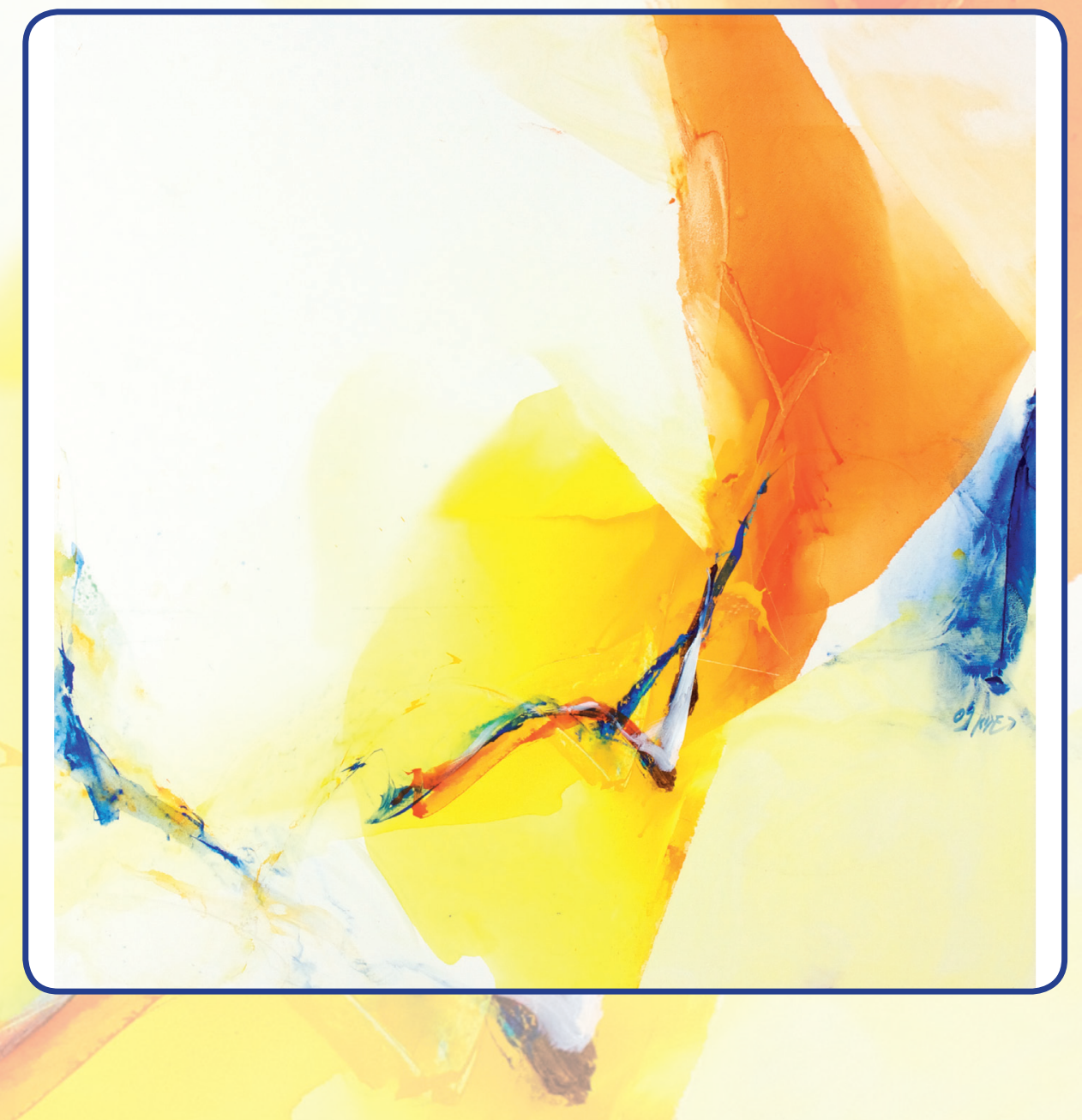

INVESTIGACIÓN 
Hommage Aux 12 apotres

Óleo sobre lienzo

$120 \times 120 \mathrm{cms}$

2009

Colección Privada

Universidad Santo Tomás 


\title{
EL ESTUDIO DEL DERECHO DESDE LA PERSPECTIVA DE LA INVESTIGACIÓN JURÍDICA
}

\author{
Rodolfo Delgado Gamboa
}

Doctorando en Derecho Universidad Externado de Colombia; Especialista en Derecho de Familia, Universidad Autónoma Bucaramanga (Col); Abogado, Universidad Santo Tomás - Bucaramanga (Col). Docente Universidad Santo Tomás Bucaramanga (Col).

E-mail: rodolfodelgadog@gmail

\section{Wilson Yesid Suárez Manrique}

Maestría en Hermenéutica Jurídica (en curso), Universidad Industrial de Santander (Col); Especialista en Derecho Procesal (en curso), Universidad Santo Tomás - Bucaramanga (Col); Abogado, Universidad Santo Tomás - Bucaramanga (Col).

Docente Universidad Santo Tomás Bucaramanga (Col).

E-mail: wilsonyesidsuarez@gmail.com

\section{Resumen}

El presente escrito muestra una visión de la investigación jurídica desde la especialización y la trifurcación que las concepciones positivisantes insertaron en el derecho. Se describen las principales concepciones acerca del derecho para, a partir de ello, ubicar el campo propio de la investigación jurídica, que permita deslindarla de los estudios que puedan darse en los cantones de la filosófica política o de la sociología jurídica. Con lo cual, se cree posible poder presentar una visión más nítida de los principales elementos que giran en torno al tópico de la investigación en el derecho, como investigación jurídica.

\section{Palabras clave}

Investigación jurídica, validez, eficacia, justicia, empirismo, racionalismo, positivismo, ciencia y formulaciones jurídicas.

\begin{abstract}
This paper shows an overview of legal research from the expertise and the views positivisantes trifurcation inserted on the right. Describes the main ideas about the right to, from this, locate the proper field of legal research, to distinguish it from studies that may be in the cantons of political philosophy or sociology of law. Thus, it is believed possible to provide a clearer view of the main elements that revolve around the topic of research in law, and legal research.
\end{abstract}

\section{Keywords}

Legal research, validity, effectiveness, fairness, empiricism, rationalism, positivism, science and legal formulations. 



\section{EL ESTUDIO DEL DERECHO DESDE LA PERSPECTIVA DE LA INVESTIGACIÓN JURÍDICA*}

Rodolfo Delgado Gamboa ; Wilson Yesid Suárez Manrique

La idea de escribir el presente artículo surgió al interior del grupo de investigación Neoconstitucionalismo y Derecho. Pues, fácilmente, al interior de las distintas sesiones de investigación que allí se realizan, puede rastrearse, en las posiciones teóricas de algunos de sus miembros, la existencia de diversas concepciones sobre los aspectos esenciales de la investigación en el derecho. Posiciones que, llevadas a un cierto grado de abstracción, tomaban como puntos de referencia el empirismo o el racionalismo y representaban la clásica pugna entre el platonismo y el aristotelismo. Como puede suponerse, acá no se pretende solucionar tal conflicto, sino, simplemente, de forma general, tomar partido de uno de los dos extremos y tratar de fundamentar tal elección.

La dicotomía de posiciones signada, tiene como génesis próximo el proceso de positivización llevado a cabo en la modernidad temprana, el cual, conllevó a la trifurcación de la reflexión jurídica ${ }^{1}$. Dicho proceso implica la especialización de los cantones epistemológicos alrededor de lo jurídico. La filosofía política, la sociología

\footnotetext{
* Producto de la construcción del marco teórico de la línea de investigación Neoconstitucionalismo y Convivencia Pacífica del Grupo Neoconstitucionalismo y Derecho. Facultad de Derecho. Universidad Santo Tomás, Seccional Bucaramanga.

1 Cfr. MEJÍA QUINTANA, Óscar. Elementos para una reconstrucción del estatuto epistemológico de la filosofía del derecho, en Humanitas (No. 33). Nuevo León: Centro de Estudios Humanísticos, Universidad Autónoma de Nuevo León, 2006. MEJÍA QUINTANA, Óscar, La problemática iusfilosófica de la obediencia al derecho y la justificación Constitucional de la desobediencia civil. Bogotá: Universidad Nacional de Colombia, 2001.
} 
o sociología jurídica y la teoría jurídica sectorizaron el objeto que antes era propio del saber totalizador. Tal distribución de los objetos de estudio ha sido horadada por un sinfín de críticas, de quienes románticamente confían en la integralidad del desarrollo del conocimiento jurídico. Las principales críticas, parecen ser: el reduccionismo epistemológico y el desdibujamiento de la reflexión de la filosófica práctica desde su integralidad. Contra tales críticas parece ser suficiente argüir tres ideas generales. La primera, la diferencia en la naturaleza del objeto difícilmente posibilita un desarrollo adecuado del proceso, los esfuerzos se centrarían más en hacer consideraciones conmensurables o adecuaciones procedimentales que en un desarrollo en cuanto tal. La segunda, la historia ha mostrado que la sectorización ha implicado grandes avances en cada uno de los objetos, la división de trabajo trae como consecuencia la especialización del conocimiento; la integralidad especulativa trae como consecuencia la regresión y la idealización. La tercera, desde la sectorización de lo jurídico pueden efectuarse reflexiones que, necesariamente, impliquen de manera tangencial las demás esferas de la reflexión práctica, en dosis adecuadas.

Lo anterior, traído al campo de la investigación significa que no se acrecientan las concepciones investigativas en lo jurídico sino que se desmejoran cuando se entremezclan sus fronteras. El campo de la investigación jurídica ha sido horadado por una serie de conceptos traídos de otros cantones epistemológicos impropios a la naturaleza del derecho, que han contribuido al desdibujamiento de la investigación jurídica. Lo cual, además de hacer franquear las nociones más básicas de la investigación jurídica, le ha hecho perder sus referentes y finalidades lógicotrascendentales.

El presente trabajo, de carácter meta-teórico, tiene como finalidad principal describir los elementos más importantes de la investigación jurídica $\mathrm{y}$, en lo posible, mostrar cómo las diferentes concepciones que se tengan del derecho, de la forma de aprensión del conocimiento y de la ciencia se han mezclado en un proceso complejo y contradictorio. Pues, el estudio del derecho ha estado ligado no sólo a la concepción del derecho que presupone, sino también, a los paradigmas de las teorías del conocimiento y de la ciencia.

Para llevar a cabo lo anterior, se divide el escrito en cinco secciones. En la primera, se describen brevemente, las principales concepciones acerca de cómo se ha entendido el derecho. Ello, se hace necesario como sustento teórico de lo que se desarrolla a continuación. Pues, las elucubraciones acerca de la investigación jurídica, obviamente, presuponen, si se quiere evitar confusiones o discusiones bizantinas, una concepción del derecho. No puede entenderse la investigación jurídica sin suponer una concepción del derecho, inclusive, puede pensarse que no existe investigación jurídica para algunas concepciones del derecho.

En la segunda sección, se presentan sintéticamente cuatro ideas relacionadas acerca del conocimiento y la ciencia. La primera, refiere al paradigma clásico de 
las concepciones principales acerca de las formas primordiales de aprehensión en el conocimiento. La segunda, refiere a determinados juicios de la razón teórica que se insertan de manera adecuada a cada uno de los extremos de los modos de aprehensión en el conocimiento. La tercera, refiere a las implicaciones que lo comentado en los puntos anteriores han efectuado sobre los movimientos científicos denominados como positivismo y positivismo lógico. La cuarta, respecta a una clasificación sencilla, relacionada con los tres puntos anteriores, acerca de la ciencia.

En la tercera sección, se presentan algunas consideraciones acerca de la relación entre el derecho y las ciencias. Para ello, se revisa la relación del derecho con las concepciones clásicas de ciencia, y se insinúa cómo la investigación en el derecho ha estado orientada a las formas clásicas de conocimiento y ciencia, y cómo tal aseveración ha representado, prima facie, un proceso dialéctico y contradictorio.

La cuarta sección del escrito, se concreta principalmente a mostrar las principales características de la investigación jurídica. Para ello, se considera lo relativo al objeto de estudio, los principales problemas que puede presentar y la finalidad del la investigación jurídica.

En quinto lugar, se revisa el lugar de los juicios de valor en la investigación jurídica. Situación que se hace necesaria debido a: las crecientes modas de diferentes teorías que parecen, de una u otra forma, asentir lo valorativo en el derecho, no sólo dentro del proceso de creación del mismo sino, también, en su aplicación y estudio, entre otras cosas, por la deslegitimación de lo jurídico positivo y a las críticas de seudo-objetividad en el conocimiento.

\section{Modos en los que se ha pensado el derecho}

La concepción de investigación jurídica presupone la concepción del derecho. Lo que se entienda por investigación jurídica, incluso la posibilidad de entender algo por ello, hace necesario, fincar una noción acerca del derecho. Pues, según ella se determina aquella. Además de evitar confusiones se llega a mejor entender de la investigación: el objeto, los problemas y su finalidad.

Se ha dicho, con cierta sutileza, que la noción del derecho, a trazos generales, debe responder a diversas cuestiones. Como la concepción es compleja, se ha tratado de integrar por la respuesta a diversos asuntos constitutivos de tal noción. Podría decirse, por ejemplo, que la noción del derecho debe responder a cuestiones como:

“a) cuáles son sus componentes básicos; b) qué se entiende por derecho válido y cómo se trazan los límites entre el derecho y el no derecho; c) qué relación guarda el derecho con la moral y con el poder; d) qué funciones cumple el derecho, qué objetivos y valores deben -o pueden- alcanzarse con él; e) cómo puede conocerse 
el derecho, de qué manera puede construirse el conocimiento jurídico; f) cómo se entienden las operaciones de producción, interpretación y aplicación del derecho"2.

Lo anterior puede parecer algo complejo, redundante y poco claro. Algunas cuestiones son presuposiciones o respuestas de otras. Por ejemplo: los límites entre el derecho y el no derecho pueden depender de la relación del derecho con la moral, relación que podría, también, implicar las distinciones entre derecho válido e inválido, o la relación con los valores; situaciones similares aplican en los demás elementos constitutivos referidos. Elementos particulares pueden englobarse en concepciones un poco más generales. Empero, nadie negaría el interés que puede suscitar referir los elementos constitutivos de la noción del derecho.

Se considera que una forma más simple, en la cual se puede englobar los anteriores predicamentos, puede ser la de afirmar que la concepción del derecho debe corresponder a una noción flanqueada de cuestiones acerca de la ontología, la metodología y la axiología jurídica. La noción de derecho, en este estadio, implica una respuesta a estas tres cuestiones. A la primera, le compete determinar qué es el derecho, su definición; lo cual sirve para diferenciar el derecho del no derecho, el válido del no válido y qué elementos lo constituyen, entre otras cosas. A la segunda, le corresponde determinar "el problema de los medios o caminos que hay que seguir para alcanzar el derecho; también el problema de los razonamientos de los juristas", es decir, lo concerniente a: la producción, interpretación, aplicación y argumentación en el derecho. Y, a la tercera, "llegar a captar los valores en los que se encuentra lo

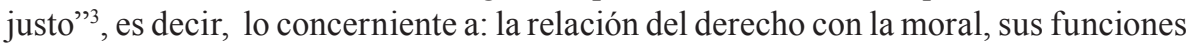
$\mathrm{y}$ fines.

Lo anterior se puede simplificar aún más. Si se quiere examinar la noción del derecho desde una óptica más simple y clásica, se tendrá que analizar dicha concepción desde un grado de abstracción más elevado. En este sentido, se respecta las concepciones del derecho pero ya no tanto desde un punto de vista estructural constitutivo o referido al ser, el método y los valores, sino más desde el punto de vista de un dúo o trío de elementos definitorios, donde el acento de uno ellos determina los demás elementos que se le quieran endilgar a la concepción del derecho. Estos elementos son: la justicia, la validez y la eficacia ${ }^{4}$.

La noción del derecho se da de conformidad con el acento o el peso que se le otorgue a cada uno de los elementos esenciales constitutivos del derecho. Podría decirse, en otros términos, que la problemática del concepto del derecho gira en torno a tres conceptos relativos a las normas: 1) si es justa o injusta; 2) si es válida

2 ATIENZA RODRÍGUEZ, Manuel, y FERRAJOLI, Luigi. Jurisdicción y Argumentación en el Estado Constitucional. México: Universidad Nacional Autónoma de México. 2005. p, 15.

3 VIGO, Rodolfo Luis, El Iusnaturalismo actual. México: Fontamara. 2003, p 18-19.

4 BOBBIO, Norberto. Teoría general del derecho. Santa Fe de Bogotá: Editorial Temis. 1997, p. 20. 
o inválida; 3) si es eficaz o ineficaz. Cada uno de estos problemas han encontrado solvencia en diferente acento en las tres concepciones clásicas del derecho: las teorías iusnaturalistas, positivistas y las realistas. En las primeras, el acento del derecho recae sobre la correspondencia con valores morales, en las segundas, el acento del derecho recae sobre el procedimiento y la competencia en la producción del derecho $\mathrm{y}$, en las terceras, el acento recae en el obedecimiento del derecho o la sanción por su incumplimiento.

De forma más abreviada, aún, lo relativo a la noción de derecho se puede concebir bajo el código binario de lo necesariamente justo y de la negación de su necesidad. Bajo esta óptica "el problema central de la polémica acerca del concepto del derecho es la relación entre el derecho y la mora". "A pesar de una discusión de más de dos mil años, aún existen dos posiciones básicas: la positiva y la no positiva." ${ }^{5}$ En esta concepción el tridente de Bobbio (Que también es característico de autores como Óscar Mejía ${ }^{6}$ o Manuel Atienza ${ }^{7}$ ) se divide primariamente en dos posiciones que las engloban: las teorías positivistas ${ }^{8}$ y las teorías no positivistas ${ }^{9}$. Cada una de tales teorías es caracterizada por una tesis que toma como referencia el concepto de moral y su relación con el derecho. Es así, que puede hablarse de la tesis de la no vinculación necesaria y la tesis de la vinculación necesaria, para definir las teorías positivistas y no positivistas.

Las teorías positivistas sostienen la tesis según la cual no existe una vinculación necesaria entre el concepto de derecho y la moral. "No existe ninguna vinculación conceptual necesaria entre derecho y moral, entre aquello que ordena el derecho y aquello que exige la moral o entre el derecho que es y el derecho que debe ser." Esta vinculación no necesaria, no descarta que pueda existir una vinculación entre el

5 ALEXY, Robert. El concepto y la validez del derecho. Barcelona: Gedisa. 2004, p. 13.

6 MEJÍA, Óscar. Elementos para una reconstrucción del estatuto epistemológico de la filosofía del derecho, en Humanitas (No.33), Nuevo León: Centro de Estudios Humanísticos, Universidad Autónoma de Nuevo León, 2006. MEJÍA, Óscar, La problemática iusfilosófica de la obediencia al derecho y la justificación Constitucional de la desobediencia civil. Bogotá: Universidad Nacional de Colombia, 2001.

7 ATIENZA, Manuel, y FERRAJOLI Luigi, Jurisdicción y Argumentación en el Estado Constitucional de Derecho, en el Derecho como argumentación, México: Universidad Nacional Autónoma de México, 2005.

8 Llega a un concepto de derecho puramente positivista quien excluye totalmente la corrección material y apunte sólo a la legalidad conforme al ordenamiento/o la eficacia social". ALEXY, Robert. El concepto y la validez del derecho. Barcelona: Gedisa. 2004, p, 21.

9 "La cuestión consiste en saber cuál de los conceptos resulta ser el más correcto o adecuado. Quien desee responder a esta pregunta tiene que relacionar tres elementos: el de la legalidad conforme al ordenamiento, el de la eficacia social y el de la corrección material". "Quien no concede ninguna importancia a la legalidad conforme al ordenamiento y a la eficacia social y tan sólo apunte a la corrección material obtiene un concepto de derecho puramente iusnatural o iusracional". ALEXY, Robert. El concepto y la validez del derecho. Barcelona: Gedisa. 2004, p, 21. 
derecho y la moral de otro tipo, por ejemplo, una vinculación contingente o eventual. Simplemente afirma que el derecho para ser derecho no necesita estar necesariamente vinculado con la moral. La moral no es un elemento definitorio del derecho. Por tanto, puede existir derecho que no sea justo.

Al descartar del derecho una vinculación necesaria con la moral, quedan para definirlo los otros dos elementos señalados: la legalidad y la eficacia. Es decir, que en las concepciones positivistas la concepción del derecho se da no en relación a la moralidad sino en relación a la legalidad o a la eficacia. "Las diferentes variantes del positivismo resultan de las diversas interpretaciones y del peso que se le dé a estos dos elementos definitorios"10. Por tanto, se dice que existen dos grandes tipos de teorías positivistas según efectúen el acento en la legalidad o en la eficacia.

Las concepciones positivistas que acentúan la legalidad pueden entenderse dentro de las concepciones clásicas del positivismo normativista. Uno de los principales representantes de esta corriente es Austin, para quien el derecho son órdenes del soberano respaldadas con amenazas, tales son órdenes legales por cuanto han sido dictadas por la persona que tenía la autoridad para ello: el soberano. Son también clásicos ejemplos de esta concepción normativa del derecho: Kelsen y Hart. Un ejemplo canónico de esta concepción de derecho que descarta la moral es el establecido por Kelsen.

"Derecho y justicia son conceptos diferentes. El orden político aparece como problema ético. En cuanto lo distinguimos de la justicia, el orden jurídico aparece como derecho positivo (...). Liberar el concepto del derecho de la idea de la justicia es difícil, porque ambos se confunden en el pensamiento político no científico". "La tendencia a identificar el derecho con la justicia es la tendencia a justificar un orden social dado. No se trata de una tendencia científica sino política"11.

Refiriéndose al carácter dinámico de la norma fundante, Kelsen manifiesta: “de ahí que cualquier contenido que sea, puede ser derecho"12.

10 Ibídem., p. 14.

11 KELSEN, Hans, Teoría General del Derecho y del Estado, México: Universidad Nacional Autónoma de México, 1995, p. 6.

12 La norma fundante es una norma suprema, presupuesta, es el fundamento de las demás normas del sistema y dota a éste de unidad, constituye "un sistema de normas, un orden normativo." Es fuente de validez de las normas que constituyen un sistema jurídico. Empero, ese fundamento común de validez para los sistemas jurídicos puede ser de dos tipos diferentes: un tipo estático y un tipo dinámico. Las normas del tipo estático "valen por su contenido", "pues el contenido de las normas puede ser subsumido como de lo particular a lo general". En tanto esas normas fundantes de tipo estático prestan el fundamento de la validez, y la validez del contenido de las normas que conforman el ordenamiento. En contrapartida a lo anterior, existen normas que prestan el fundamento de validez al sistema jurídico, pero no refieren al contenido, en tanto se trata de tipos de normas con "un principio dinámico". Pues en esta clase de normas, ya no se tiene en cuenta el contenido- situación grave si se tiene en vista que ellas son del tipo de las utilizadas en el derecho según Kelsen-. Al no tenerse en cuenta el contenido, puede notarse que éste puede ser cualquiera, y al ser cualquiera es dinámico. Cfr. KELSEN, Hans, Teoría Pura del Derecho, México: Editorial Porrúa, 2000, p, 201- 212. 
Las concepciones positivistas que acentúan la eficacia pueden entenderse dentro de las concepciones clásicas del realismo jurídico o de la sociología jurídica. Son clásicos ejemplos de estas concepciones positivistas las elucubraciones de Kantorowicz, Alf Ross, Theodor Geiger, Ernst Rudolf Bierling, Niklas Luhmann y Llewellyn. Según uno de los principales representantes y fundadores de esta corriente, Kantorowicz, la importancia del derecho radica en las decisiones tomadas por los órganos judiciales acorde con la realidad social, más que en normas válidas. Según él:

"Los ideales de la legalidad, de la pasividad, de la fundación racional, del carácter científico, de la seguridad jurídica y de la objetividad parecen incompatibles con el nuevo movimiento." "Si la ciencia del Derecho reconoce el Derecho libre, la jurisprudencia no puede ya fundarse exclusivamente sobre el Derecho estatal. Si la ciencia jurídica posee fuerza creadora, la jurisprudencia no será por más tiempo mera servidora de la ley. Si la ciencia en cada momento tiene en cuenta lagunas, la práctica no podrá resolver jurídicamente cualquier supuesto"13.

Por otra parte, las teorías iusnaturalistas sostienen la tesis según la cual existe una vinculación necesaria entre los conceptos de derecho y moral. Debe existir una conexión necesaria entre aquello que ordena el derecho y aquello que exige la moral o entre el derecho que es y el derecho que debe ser. Esta vinculación necesaria no sólo requiere una vinculación contingente o eventual sino imperativa. Por tanto, no puede tenerse como derecho aquellas prescripciones que pese a que son legales o eficaces contradicen la moral o no están de acuerdo con ella. La moral es, bajo esta óptica, el elemento definitorio del derecho. Son ejemplos característicos de estas concepciones las nociones del iusnaturalismo racionalista de Aristóteles, Jean Bodin (1530-1596), Tomás de Aquino (1124-1274) y Michel Villey (1914-1988). Según éstos últimos:

"Los fines de la justicia, coinciden idénticamente con los del derecho"14.

"Como la ley se constituye primariamente por el orden al bien común, cualquier otro precepto sobre actos particulares no tiene razón de ley sino en cuanto se ordena al bien común (...). Y, por eso, el objeto de la justicia, a diferencia de las demás virtudes, es el objeto específico que se llama lo justo. Ciertamente, esto es el derecho. Luego, es manifiesto que el derecho es el objeto de la justicia. ${ }^{15}$

13 KANTOROWICZ, Hermann. La lucha por la ciencia del derecho, trad. de Werner Goldschmidt, en Savigny, Friedrich Karl von et al., La ciencia del derecho, Buenos Aires: Editorial Losada: 1949, p, 361-367.

14 VIGO, Rodolfo Luis, El Iusnaturalismo actual. Biblioteca de ética, filosofía del derecho y política. México. 2003. p. 35.

15 TOMÁS DE AQUINO, Suma Teológica, I, II, cuestión 57, art. 1. 


\title{
Conocimiento y Ciencia
}

\author{
Empirismo y Racionalismo
}

En la teoría clásica del conocimiento parecen existir dos puntos extremos en lo relativo a la forma como se adquiere el conocimiento. En un extremo se encuentra el empirismo, y, en el otro, el racionalismo. Ello caracteriza el clásico conflicto entre el platonismo y el aristotelismo. No obstante, lo anterior no niega la existencia de puntos intermedios que se tensionan entre los radicales; tal es el caso del: intelectualismo, el criticismo y el pragmatismo. A continuación se describen las características principales, de las concepciones más representativas, de los dos extremos signados.

\section{Empirismo}

Por concepciones, principalmente, de Francis Bacon ${ }^{16}$, John Locke ${ }^{17}$ y David Hume $^{18}$ el acento sobre la fuente del conocimiento humano recayó en lo sensible, en la experiencia. Hume desarrolló el empirismo de Locke. Él, de forma impetuosa, pregonaba por un conocimiento empírico sobre el racionalista. Por eso, fue y es conocido como "el gran crítico del racionalismo". Según él “la conciencia cognoscente no saca sus contenidos de la razón, sino exclusivamente de la experiencia. El espíritu

16 Bacon (1561 -1626) se interponía en el Nuevo Organon a la concepción clásica deductivista del Órganon Aristotélico. Sus concepciones se dividían en dos partes: una destructiva, y, otra, constructiva. En la primera, alegaba por la abolición de los ídolos o perjuicios -de tribu, caverna, foro o teatro-, los cuales deformaban la aprensión del conocimiento. En la segunda, alegaba por la construcción del conocimiento tomando, principalmente, el método inductivo, el cual mediante tablas o registros implicaba la verificación de las inducciones, lo cual puede ser tomado como el fundamento del comúnmente llamado método inductivo-hipotético-deductivo.

17 Locke (1632-1704), por su parte, criticaba el cognitivismo ético y la consideración sobre las ideas innatas. Según él, podría fácilmente demostrarse que los valores éticos eran relativos; al analizar las consideraciones generales que diferentes sociedades o grupos tenían en un mismo lapso, o la misma agrupación había tenido en diferentes lapsos quedaba abolida la consideración de valores éticos absolutos, validos para todas las agrupaciones en cualquier tiempo. Como ciertas concepciones éticas eran relativas sus determineidades se contradecían. En segundo lugar, "combate con toda decisión la teoría de las ideas innatas. El alma es un "papel blanco", que la experiencia cubre poco a poco con los trazos de su escritura". La experiencia, puede ser de dos clases o puede ser, mejor dicho, utilizada en dos sentidos: una experiencia externa y una experiencia interna. Hay una experiencia externa (sensación) y una experiencia interna (reflexión). "Los contenidos de la experiencia son ideas o representaciones, ya simples, ya complejas". Aunque todos los contenidos del conocimiento proceden de la experiencia $\square$ enseña Locke $\square$, su valor lógico no se limita en modo alguno a la experiencia. Hay, por el contrario, aunque a primera vista suene extraño para un empirista, verdades que son por completo independientes de la experiencia y, por tanto, universalmente válidas. Es decir, existen ámbitos en los cuales la experiencia no viene a ser el principal motor de obtención del conocimiento. Un ejemplo de estas consideraciones que escapan al aspecto empírico es el de las matemáticas.

18 Hume (1711-1776) quería expandir los métodos de Newton a la ciencia del hombre. 
humano está por naturaleza vacío; es una tabla rasa, una hoja por escribir en la que escribe la experiencia"19. La principal fuente de conocimiento, bajo esta óptica, son las percepciones ${ }^{20}$. Lo anterior le sirve a Hume para concebir el principio según el cual: "todos nuestros conceptos han de poder reducirse a algo intuitivamente dado." Las percepciones están condicionadas o tienen su fuente inmediata en las impresiones. Las ideas, a su vez, dependen de las impresiones. Son reproducciones imperfectas de las impresiones. Así pues, pueden existir dos tipos de conocimiento: la relación entre ideas y las cuestiones de hecho. El primero es propio de las matemáticas y la lógica ${ }^{21}$, y el segundo propio de la física.

\section{Racionalismo}

En posición, prima facie, contraria a la del empirismo, se gestó la corriente racionalista. Por concepciones que sobresalieron en el pensamiento de Aristóteles y Descartes, se consideró que el conocimiento se adquiría, no tanto de la experiencia sino, más bien, tenía como fuente a la razón.

Descartes quería, entre otras cosas, responder los embates dados en contra de la filosofía, deseaba redimirla en trascendencia. En ese orden de ideas la reivindicación de la filosofía como ciencia conllevaba a la implementación de un método científico. Para llevar tal empresa a buen término, decidió, inspirado en la matemática, implementar un método racionalista para la filosofía, justificando ello, en las aporías del estancamiento de tal conocimiento y la falta de certeza conocimiento sensible. Dentro de las ciencias que más han sido alabadas y que hacen gala de su exactitud y estabilidad se encuentra como parte de la matemática la geometría euclidiana. Al observar esto, Descartes quiso inspirarse en ella para establecer un método mediante el cual se pudieran sentar pilares fundamentales de un conocimiento analógico al geométrico. Esto, en últimas, se conjugó en un procedimiento de cuatro eslabones tan simples como conocidos: la evidencia racional, el análisis, la síntesis y la comprobación o verificación. Así pues, Descartes descuida el conocimiento sensible y se centra en un conocimiento racional. Para lograr esto, "el punto de partida es un primun verum, que no puede ser anulado ni siquiera por medio de la duda".

19 HESSEN, Johannes, Teoría del Conocimiento, Editorial Tomo, México, 2003, p. 26.

20 Hume divide las percepciones de Locke en impresiones e ideas. "Por impresiones entiende las vivas sensaciones que tenemos cuando vemos, oímos, tocamos, etcétera". "Por ideas entiende las representaciones de la memoria y de la fantasía" HESSEN, Johannes, Teoría del Conocimiento, Editorial Tomo, México, 2003, p. 30.

21 "Hume reconoce en la esfera matemática un conocimiento independiente de la experiencia y, por ende, universalmente válido. Todos los conceptos de este conocimiento proceden también de la experiencia, pero las relaciones existentes entre ellos son válidas independientemente de toda experiencia. (...). Aunque no hubiese habido nunca un triángulo, las verdades demostradas por Euclides conservarían por siempre su certeza y evidencia. Así pues, al lado del conocimiento sensible es asible el conocimiento lógico. A continuación, se especifica estos tipos de conocimiento de conformidad con los tipos de juicios a que dan lugar". Ibídem. 
"El desarrollo ulterior se hace de acuerdo con el modo de la geometría, es decir, conforme a los cánones de la primera ciencia estrictamente demostrable $\mathrm{y}$, en lo posible, mediante largas deducciones en cadena"22.

\section{Juicios analíticos, sintéticos y sintéticos-analíticos}

Hume refiere, quizás de la forma más refinada y reconocida, el tema de los juicios en el conocimiento teórico. Reseña principalmente dos clases de juicios: los analíticos y los sintéticos. En los juicios analíticos el predicado está dentro del sujeto. Éstos son a priori. Son universalmente válidos y necesarios. No aumentan el conocimiento. No son contrastables empíricamente. Un clásico ejemplo de esta clase de enunciados es: todos los radios de una circunferencia son iguales.

Por su parte, en los juicios sintéticos el predicado no está dentro del sujeto, pues para llegar a él hace falta algo más que la simple referencia al sujeto. Éstos son a posteriori. No son universales y necesarios, sino particulares y contingentes, pues no valen siempre ni en todo momento ni bajo diversas circunstancias. Para la comprobación se hace necesaria la contrastación empírica. Estos juicios aumentan el conocimiento. Un clásico ejemplo de esta clase de enunciados es: "los leopardos son animales que pueden correr hasta 60 kilómetros por hora".

Posteriormente, Kant complementa la anterior clasificación. Considera que las ciencias ostentan juicios universales y necesarios pero que no son a priori. Es decir, que no pueden fácilmente implicarse en la categoría de los analíticos o de los sintéticos. El predicado no está dentro del sujeto, ni requiere contrastación empírica, pues la verdad que ellos ostentan es evidente. El clásico ejemplo Kantiano en este sentido es: "La distancia más cercana entre dos puntos es una línea recta". No puede decirse que el predicado esté inmerso en el sujeto, ni que sea necesario contrastar empíricamente tal juicio a efectos de demostrar su verdad. Tal juicio es universal y necesario, pese a que no es a priori, por tanto, ante tales juicios se abre una nueva categoría. Tal categoría viene a ser denominada como juicios sintéticos analíticos. Según Kant, los juicios sintéticos a priori son los que en términos generales conforman las ciencias.

\section{Positivismo y positivismo lógico}

Augusto Comte ha sido en cuanto al tema de la cientificidad quizás el teórico más importante del siglo pasado. El pilar central de la cientificidad, bajo este manto, lo constituye la concepción de positivismo ${ }^{23}$.

22 VIEHWEG, Theodor. Tópica y jurisprudencia, traducción de Díez-Picazo, Luis España: Taurus. 1964, p. 27.

23 "La paternidad del término positivismo se le ha endilgado principalmente a Saint Simon y a Augusto Comte". No obstante, es irresoluble que pese a que el primero en utilizar el término "positivismo" fue Saint Simon, el que se encargó de popularizarlo fue Comte. 
Comte, en cierto sentido, puede verse como un continuador de la revolución de Bacon. Quería interponer a lo que él llamaba oscurantismo metafísico y teológico, una visión positiva, una visión de lo puesto, de lo real. En este orden de ideas refería que el conocimiento humano había transcurrido por tres estados: el metafísico, el teológico y el positivo. De forma general podría decirse que en los dos primeros el conocimiento provenía de mitos, cuestiones metafísicas o dogmas religiosos, no obstante, en el positivo podría hablarse de un verdadero conocimiento, real, verificable, científico.

Aunque la conceptualización del positivismo resulta problemática, podría decirse, así suene a la ligera, que éste se caracteriza por cuatro tesis principales. La primera, llamada de la exclusividad, según la cual: todo el conocimiento que no sea científico no es válido, es decir, se reduce la validez a la cientificidad. La segunda, de la función descriptiva, según la cual: el "concomimiento científico es puramente descriptivo" ${ }^{24}$. La tercera, de la extensión del cientificismo, según la cual: el conocimiento científico debe "extenderse a todos los campos del saber, incluido el hombre" ${ }^{25}$. La cuarta, la unicidad del método, según la cual: el único método válido es el de las ciencias naturales, en donde se hace importante la determinación de la causalidad adecuada.

El círculo de Viena, con Hans Hass, Rusell y Carnap, entre otros, ha expuesto, en términos generales, una visión de la concepción científica que puede ser denominada como neopositivismo o positivismo lógico ${ }^{26}$. La cual, puede decirse, constituye una nueva concepción de la ciencia desde, especialmente, las implicaciones que intentan insertar de manera vehemente la matemática y las concepciones lógicas en las demás ciencias, de ahí el término de positivismo lógico.

De forma sintética, puede decirse, que las principales tesis del positivismo lógico son cuatro. La primera, de la aplicación a todas las ciencias de las nociones lógicas, según la cual las ciencias, en general, al igual que las ciencias formales, deben regirse por principios lógicos que expliquen las diferentes relaciones e implicaciones dadas entre los conceptos o elementos de cada una de las teorías. La segunda, del rechazo a la metafísica, según la cual: el proceso investigativo o científico no debe ser horadado por concepciones relativas a la filosofía o a las materias que no puedan ser contrastables empíricamente. La tercera, de pretensión de objetividad, según la cual: el conocimiento científico es o pretende ser objetivo, por tanto, existe rechazo en este sentido a las concepciones meramente subjetivas. La cuarta, de la unificación del método, según el cual: todas las ciencias pueden basarse en un único método, si

24 ATENCIA, José María, Positivismo y Neopositivismo, Revista Universidad de Málaga, s.f., p. 144.

25 Ibídem.

26 "El cientificismo puede definirse a la luz de cuatro postulados: fenomenalismo, nominalismo, objetividad y fe en la uni dad fundamental del método de la ciencia". IBARZÁBAL, Ignacio, El Maniaco Del Unizono. Una Crítica Al Positivismo Por Su Reduccionismo Epistemológico. Universidad de la Sabana. Bogotá: Editorial Dikaion, 2007, p. 97. 
el conocimiento objetivo es uno sólo no hay razón para buscar diferentes métodos si puede utilizarse un método para todo conocimiento ${ }^{27}$.

\section{Clases de ciencias}

La ciencia ha sido de las concepciones más trascendentes en la historia de la humanidad ${ }^{28}$. Empero, la concepción de ciencia presenta múltiples aporías. La noción de ciencia no sólo es polisémica, ambigua, denota el proceso y el producto de la actividad, sino que, además, no ostenta precisión para identificar los procesos o los productos a los cuales refiere. "Esa característica del significado de la palabra ciencia provoca grandes dificultades en el uso de la misma". No obstante, existen casos centrales de actividades o resultados denotados por esta palabra. "Nadie dudaría que las matemáticas, la física, la química, la biología, la zoología, la anatomía y la geografía son ciencias." ${ }^{29}$ Con respecto a la ética y la filosofía política la vacilación es completa. Es decir, aunque existen casos claros en los cuales es fácil determinar que algo es ciencia, existen casos de vaguedad en los cuales no es fácil determinar si se está o no en el campo de la ciencia, lo cual, conlleva, en este orden de ideas, a que la decisión de tal determinación sea arbitraria.

La realidad, o parte de ella, trata de ser representada mediante ciertas proposiciones de una teoría, "así, por ejemplo, la termodinámica sobre sistemas que interaccionan intercambiando energía, la genética mendeliana sobre la transmisión de rasgos en la generación de seres vivos, la aritmética de Peano sobre los números naturales y

27 Cfr. Atencia, José María, Positivismo y Neopositivismo, Revista Universidad de Málaga, s.f., p. 145 .

28 Como arte institucionalizado de investigación de la ciencia ha dado frutos variados. Sus productos más publicitados son, sin duda, las conquistas tecnológicas que han trasformado las formas tradicionales de la economía humana a un ritmo acelerado. Las principales son: el logro de un conocimiento teórico y general a las condiciones fundamentales que determinan la aparición de diversos tipos de sucesos y procesos; la emancipación de la mente del hombre de las supersticiones antiguas, en las cuales se basan a menudo las costumbres bárbaras y los temores opresivos; el socavamiento de los frutos intelectuales de los dogmas morales y religiosos, con el debilitamiento concomitante de la cubierta protectora que suministra la certeza de los hábitos irracionales el mantenimiento de las injusticias sociales, y, en un plazo de mayor generalidad, el gradual desarrollo, de entre un número cada vez mayor de personas, de un temperamento intelectual inquisitivo frente a las creencias tradicionales, desarrollo frecuentemente acompañado por la adopción en dominios anteriormente inaccesibles al pensamiento crítico sistemático, de métodos lógicos para juzgar, sobre la base de datos de observación confiables, los méritos de suposiciones alternativas concernientes a las cuestiones de hecho o al curso de la acción más adecuada. SANTIAGO NINO, Carlos. Consideraciones sobre la Dogmática Jurídica. México, Universidad Autónoma De México. 1974. p, 15.

29 NAGEL, Ernest. La estructura de las ciencias, Buenos Aires: Paidos, 1968, p. 11. 
sus propiedades" ${ }^{\prime 30}$. Que determinadas proposiciones puedan ser consideradas como científicas es un asunto complejo. De forma general, la palabra o la concepción de ciencia es usada en diferentes estadios y con diferentes significados. Por tanto, la clasificación de ciertos enunciados bajo tal adjetivo, depende, claro está, de lo que signifique ciencia: una concepción amplia sobre la ciencia conlleva a que muchas actividades puedan ser denominadas como científicas, una concepción estricta acerca de la ciencia conlleva que muchas sean excluidas.

Si se toma una simplista clasificación sobre las ciencias en formales y empíricas, a las primeras corresponden aquellas ciencias que tienen por objeto el análisis lógico y sistémico de diversos juicios. "Una investigación desde el punto de vista de la sintaxis se ocupa del aspecto lingüístico formal" 31 . En este estadio resulta importante la noción de cálculo. Donde las nociones de reglas de formación y de transformación se aplican. "El ámbito total de las matemáticas está constituido sólo por reglas de formación y de transformación. Por consiguiente, la matemática está constituida únicamente por cálculos." 32 . Las reglas de formación están condensadas en los axiomas ${ }^{33}$. De ellos, mediante las reglas de transformación se extraen los teoremas que representan los axiomas. "Los teoremas no contienen información nueva; sólo hacen explícita información que ya estaba contenida implícitamente en los axiomas" ${ }^{34}$. De las proposiciones de las ciencias formales no puede, en sentido estricto, decirse que son verdaderas o falsas, sino, más bien, correctas o incorrectas.

Las ciencias empíricas toman ciertas determinaciones de las formales pero le adicionan una característica especial. En este entendido, existe una "vinculación conceptual entre la noción empírica de teoría con la noción formal", lo cual, "se debe a la pretensión racional de aplicar a las teorías empíricas la estructura lógica que define a las teorías formales" ${ }^{35}$. Empero, el aditivo de las concepciones empíricas se conjuga en que "las afirmaciones de las teorías empíricas tienen contenido empírico, esto es, son susceptibles de ser puestas a prueba por cierta clase de hechos". "Aquí interesa la adecuación de proposiciones de las ciencias fácticas con la realidad, de tal manera que sólo hay que establecer determinaciones acerca de la verdad de las

30 DÍEZ, José y MOULINES, Ulises. Fundamentos de Filosofía de la Ciencia, Barcelona: Ariel, 1997, p. $266-267$.

31 SCHREIBER, Rupert. Lógica del Derecho. Distribuciones Fontamara. México 1999. p. 31

32 Ibíd., p. 32

33 En realidad, una buena axiomatización se logra una vez que se ha logrado dar una versión lo más "resumida" o "concentrada" posible de una teoría, esto es, un conjunto mínimo de axiomas que sean independientes entre sí (no redundantes). Lariguet, Guillermo. La Reconstrucción de las 'Teorías Dogmático-Jurídicas' como "Cálculos Interpretados". Una exploración conceptual sobre su plausibilidad filosófica. Recuperado el 5 de octubre de 2010, de la dirección WEB: http://www. aafd.org.ar/archivos/ $15 \_$jornada_Lariguet.pdf. p. 4.

34 Ibídem

35 Ibíd., p. 5 
proposiciones"36. Es decir, que las proposiciones de las ciencias empíricas pueden ser contratadas de facto, de ellas se puede decir si son verdaderos o falsos. Si concuerdan con un estado de cosas son verdaderas y si no son falsas.

\section{La ciencia jurídica}

Establecer si el derecho es o no una ciencia es algo que ha ocupado muchas discusiones. La concepción del derecho como ciencia es algo poco pacífico, por cuanto, no se tiene, realmente, claros los dos conceptos. Ni el punto de partida ni cuáles son las precisas exigencias hacia éste ${ }^{37}$.

Según cierta posición de la doctrina existen buenos argumentos para tomar el derecho como ciencia como buenos argumentos para afirmar que el derecho no es ciencia. Ello depende del punto de referencia, de la concepción de ciencia. Luego la conclusión depende de las premisas. La determinación de las premisas, del significado de ciencia, conlleva a la determinación de la conclusión, la consideración o no consideración del derecho como ciencia. La conclusión es variable.

Si se retoma la clasificación de las ciencias en formales y empíricas, la conclusión, en primera medida, parecería obvia. El derecho no suple los condicionamientos de éstas. "Es verdad que la ciencia jurídica no puede clasificarse sin más como una ciencia empírica, y mucho menos como una ciencia formal." "De claro, que no puede entenderse como ciencia jurídica bajo los parámetros de una ciencia formal o empírica, cabe preguntarse si puede entenderse como ciencia en otro sentido".

Responder de fondo tal cuestionamiento, es como inmiscuirse en un callejón sin salida. No obstante, se han tratado de dar diversas soluciones. Quizás las más representativas sean las de entender las normas, o formulaciones jurídicas, como cálculos o como descripciones acerca de la realidad. Pero, tales soluciones parecen tropezar con problemas, prima facie, insalvables. Por la ambigüedad del lenguaje natural del que se vale el derecho, lo contradictorio de las relaciones entre formulaciones jurídicas, y la falta de acuerdo sobre cuestiones esenciales de ellas, se ha declinado la intención de convertir en cálculos los sistemas jurídicos; los tropiezos encontrados por Hobbes, Leibniz y Pufendorf, parece que aún existen. La concepción del derecho, o de las normas de éste, en sentido descriptivo, es decir, bajo el entendido que existe un sistema jurídico, o una norma del sistema jurídico que dice que tal o cual cosa debe o puede hacerse, presenta tantos problemas y puede llegar a resultados tan paradójicos y alejados de la realidad, que sólo puede concebirse como un intento de acercar al derecho con lo científico.

36 SCHREIBER, Rupert. Lógica del Derecho. Distribuciones Fontamara. México 1999, p. 121

37 Si se toma una concepción pre-moderna de ciencia el resultado es diferente a si se toma una concepción estrictamente neo-positivista.

38 ALCHOURRÓN, Carlos, y BULYGIN, Eugenio, Introducción a la metodología de las ciencias jurídicas y sociales. Buenos Aires: Editorial Astrea, 1974, p, 21. 
Lo anterior no quiere significar que el derecho no sea ciencia, ni que no lo pueda ser. Simplemente afirma que bajo los conceptos tradicionales de ciencia el derecho no empata, y que las soluciones dadas parecen que no han llevado a buen puerto.

El cuestionamiento que ahora parece ser más interesante es el de establecer qué repercusiones puede tener que el derecho sea o no considerado como ciencia. Tal vez, la principal función de la consideración de la ciencia jurídica como científica sea la de generar un efecto perlocucionario. La consideración de algo como científico tiene un efecto emotivo bastante fuerte. Empero, sus efectos son más bien de carácter político. En la comunidad actual caracterizada, entre otras cosas, por la importancia del conocimiento, desarrollar una actividad llamada "científica" es una forma de darle un plus de importancia a la actividad o producto que se despliega. En el caso de los juristas considerar la investigación del derecho como científica conlleva a darle "trascendencia social o política" a la labor investigativa. No obstante, en caso contrario, el excluir de una disciplina la labor de científica puede conllevar a presentar desestima de las actividades y del conocimiento que en él se produce.

Estas connotaciones políticas no conllevan a variar el objeto, el método ni la finalidad en la investigación jurídica ${ }^{39}$. Ni el objeto, ni el método de las matemáticas o de la biología cambian si eventualmente, se dijera que no son científicas. Si se establece o no que el derecho es ciencia, la forma de concebir la investigación jurídica no puede cambiar, pues la calificación del derecho como ciencia responde a una consecuencia de la fijación de la noción de ciencia y derecho, y no a la variación del objeto, la finalidad o el método. En este orden de ideas, si se considera ciencia o no el objeto, los problemas, el método o la finalidad de la investigación jurídica no varían. Hay implicaciones que ostentan la capacidad de variar los elementos definitorios de los procedimientos. Pero, la consideración de científica no es uno de esos elementos por lo menos aquí. Luego, su inclusión o exclusión no ostenta la potestad necesaria para variar el procedimiento de la disciplina.

Pese a lo expresado, la posición que acá se toma es la de tener a la actividad investigativa en lo jurídico como científica. Para sustentar tal afirmación, hay que efectuar dos precisiones. La primera, que la racionalidad de la investigación jurídica resulta ser limitada. Las consideraciones de que en lo jurídico pueden hacerse juicios con la exactitud de las ciencias formales o la contrastación de las naturales, debe limarse con la concepción de que la racionalidad de la ciencia jurídica es limitada. Exigir a la ciencia jurídica exactitud y precisión es híper-racionalismo. Los resultados de la investigación se acomodan al objeto, el objeto de las matemáticas o de las ciencias naturales, ostenta la capacidad para dar resultados exactos y precisos, el de lo jurídico no; por tanto, no puede exigírsele a éste los resultados de aquellas. Sería

39 Cfr. MELERO ALONSO, Eduardo. La dogmática jurídica es política. La importancia de las concepciones políticas en el trabajo de los juristas: Un acercamiento desde el derecho público. Madrid: Universidad Autónoma de Madrid. 2002. 
más objetable la investigación jurídica si un objeto que por naturaleza no tiene la capacidad de dar resultados precisos, diera resultados precisos. Habría un cambio de categoría difícil de explicar.

La segunda precisión, es que la investigación en el derecho podría ostentar tres vertientes: la del estudio de las estructuras normativas, la de la relación de éstas en torno a la eficacia y la de las relaciones morales. Acá se descarta de plano la investigación del derecho en torno al tópico moralista, como investigación jurídica. Ello, pues, se rechaza el ortodoxo cognitivismo ético o valorativo de la forma expuesta por las concepciones clásicas, y, en últimas, por cuanto, tales cuestiones corresponden más al objeto de la filosofía política que al del derecho.

En la parte final del primer acápite se dejó sentada una concepción del derecho en relación con las posturas positivistas y no positivistas. La investigación en el derecho solo se acepta bajo el modelo de las teorías positivistas, en donde se incluye el estudio de las normas desde el enfoque de su validez o de su eficacia. Empero, se hace necesario diferenciar los dos casos. La investigación del derecho en cuanto a la revisión de las estructuras normativas produce investigación jurídica. Por su parte, la investigación del derecho en cuanto a la revisión de la eficacia no produce investigación jurídica, sino más bien investigación sociológica, o si se quiere ser más sincrónico investigación socio-jurídica. La investigación jurídica tiene como guía las ciencias formales, la investigación socio-jurídica tiene como guía las ciencias naturales. Es decir, que la investigación del derecho ha presentado y puede presentar un proceso dialéctico entre lo formal y lo real.

Estas dos clases de investigación son los extremos en los cuales se ha horadado la investigación del derecho a lo largo de su historia. Véase, como ejemplo de ello, las siguientes líneas. Con Leibniz la investigación del derecho se inclinó hacia la investigación jurídica, hasta tal punto, que se pretendió la axiomatización del sistema jurídico. Montesquieu pretendió la recuperación del terreno de la investigación socio-jurídica, lo jurídico no sólo depende de lo formal sino también de su análisis contextual empírico. Sin ir tan lejos, en la época moderna en Francia y Alemania, principalmente, con la escuela de la exégesis y la jurisprudencia de conceptos se vio una inclinación del estudio de lo jurídico acentuado en la investigación jurídica, es decir, de corte formalista. Posteriormente, con la libre investigación científica de Geny y Bonnecase y las elucubraciones de Kantorowicz, se vio una inclinación de la investigación del derecho de corte socio-jurídico. Los neokantianos y, especialmente, la teoría pura del derecho, influida por las elucubraciones del positivismo lógico, inclinó la balanza hacia la investigación jurídica pues despreció todo aquel conocimiento en lo jurídico que tuviera impurezas sociales o metafísicas. Contra lo anterior, el realismo jurídico norteamericano y escandinavo, pretendieron la recuperación del terreno de la investigación socio-jurídica. 


\section{Investigación jurídica}

\section{Objeto de estudio de la investigación jurídica}

La investigación jurídica o dogmática jurídica ${ }^{40}$ presupone la distinción binaria propia de todo ordenamiento jurídico entre derecho válido y derecho no válido. La investigación jurídica parte del material normativo válido ${ }^{41}$ "de donde abstrae las condiciones limitativas de lo que es jurídicamente posible". "Análogamente a la epistemología que tiene que tomar del mismo sistema de la ciencia las condiciones del conocimiento posible, la dogmática encuentra sus condiciones de posibilidad en el sistema jurídico"42. Es decir, en una visión positivista de la investigación jurídica se tiene como objeto de estudio: las normas jurídicas válidas. Pues, constituyen la base pre-analítica de la investigación jurídica ${ }^{43}$.

La afirmación que las normas jurídicas constituyen el objeto de la investigación jurídica puede ser precisada, en el sentido de ser un poco más técnicos y afirmar que el objeto lo constituyen, más bien, las formulaciones jurídicas. Para ello, se debe partir de la distinción entre formulaciones jurídicas, normas y proporciones normativas. No obstante, para lo que acá importa tal diferenciación no se hace tan relevante ${ }^{44}$. Basta con decir, de manera tosca, que se estudian las formulaciones jurídicas entendidas

40 "La jurisprudencia se denomina dogmática no porque excluya siempre la discusión racional, sino porque toma como si fueran hechos indiscutibles las normas del ordenamiento. El dogmático no puede poner en cuestión ni criticar las normas, del mismo modo que el teólogo no cuestiona la Revelación». MELERO ALONSO, Eduardo. La dogmática jurídica es política. La importancia de las concepciones políticas en el trabajo de los juristas: Un acercamiento desde el derecho público. Madrid: Universidad Autónoma de Madrid. 2002, p. 36

41 Aunque en algunas ocasiones, inclusive, tal aspecto, el de la validez, puede ser estudiado.

42 ATIENZA, Manuel. El Futuro de la Dogmática Jurídica, Crítica de Libros, Madrid: El Basilisco, 1980, p. 64

43 Cfr. ALCHOURRÓN, Carlos, y BULYGIN, Eugenio, Introducción a la Metodología de las Ciencias Jurídicas y Sociales. Buenos Aires: Editorial Astrea, 1974, p. 21

44 Kelsen determinó el objeto de la Teoría pura después de algunas vacilaciones; al comienzo de su análisis "considera las normas jurídicas como su único objeto". Más tarde "distinguió la norma jurídica en cuanto hecho sicológico de la categoría lógica de Rechhssatz, es decir, de la proporción jurídica, que es un juicio hipotético, una apreciación normativa de hechos jurídicos". "A la base de estas distinciones se encuentran la separación estricta de categorías de Sein (ser) y de Sollen (deber) en cuanto al derecho: la norma es un Sollen, el acto de voluntad del cual ella constituye el sentido, por el contrario es un Sein" "Precisando lo anterior dijo Kelsen "toda teoría pura del derecho no debe tratar sino de la figura o estructura mental, normativa-lógica del derecho"; "la proposición jurídica es una estructura lógica, un vínculo específico entre hechos sociales, vistos bajo el ángulo de la norma jurídica y de consecuencias jurídicas que ella asocia a esos hechos. En cuanto a tales, las proposiciones jurídicas elaboradas por la ciencia, la dogmática, a partir de normas jurídicas, deben ser analizadas en su estructura por la teoría del derecho. Sobre este punto, Kelsen no es muy claro. Petev, Valentín. Metodología y Ciencia Jurídica en el Umbral Del Siglo XXI. Traducción de Luis Villar Borda. Bogotá: Universidad Externado de Colombia, 1996, pp. 96-97 
como los enunciados lingüísticos mediante los cuales se da a conocer el derecho. No obstante, en adelante, por razones de comodidad, normas y formulaciones jurídicas, serán utilizadas como sinónimas.

La cuestión por qué las formulaciones jurídicas son el objeto de estudio de la investigación jurídica, aunque se funda en un presupuesto de concepción de derecho, puede parecer arbitraria. La dogmática jurídica suele caracterizarse por la prohibición de negar ciertos puntos de partida, es decir, por ser una disciplina que considera ciertas proposiciones, de por sí, arbitrarias, como superiores a cualquier crítica, y renuncia al postulado de la investigación independiente ${ }^{45}$. El derecho cercena su objeto de estudio, al reducirlo a las formulaciones jurídicas ${ }^{46}$. Es la intención de reducir lo verdadero a lo asible en un primer momento, a lo conceptualizable $a$ priori. El positivismo en este sentido escoge arbitrariamente una faceta de la realidad jurídica, excluye las demás. Pues, para los juristas las normas o las formulaciones jurídicas son dogmas ${ }^{47}$.

Esta delimitación arbitraria del objeto de estudio de la investigación jurídica, es útil para deslindar aéste desde un punto de vista temporal, y establecer los principales enfoques y los respectivos elementosconstitutivos del objeto de estudio. En este entendido se establece una delimitación temporal del objeto de estudio, cuando se desliga de él, un momento antecedente y un momento posterior. En los momentos antecedentes al establecimiento del objeto de estudio, es decir, en la producción del derecho, se hacen relevantes consideraciones pragmáticas, ético-políticas, morales y económicas. En cambio en el momento posterior, el de la eficiencia del derecho, se hacen importantes revisiones económicas, consecuencialistas, o empíricas.

45 Cfr. ATIEnZA, Manuel. El Futuro de la Dogmática Jurídica, Critica de Libros, Madrid: El Basilisco, 1980, p. 64

46 Otra posición dice que: "Su incoherencia radica en clamar por la razón, al tiempo que escoge arbitrariamente una faceta de la realidad jurídica, excluyendo las demás. Invocando los principios cientificistas, recurre a su mayor enemigo, las valoraciones, para establecerlas como el punto de partida de toda su teoría. Así, deja entrar por la ventana, subrepticiamente, aquello a lo que públicamente le ha negado paso por la puerta. Con su ideología crítica, no hace otra cosa que valorar al considerar que ese derecho que es, es bueno por el sólo hecho de serlo. Y esto, mediante una interpretación muy particular de cuál es el derecho que es. Sin fundamentos contundentes se impone el dogma de que sólo es derecho aquel que surge de ciertos procedimientos formales. Nos encontramos con dos reduccionismos anidados. El primero al conceptualizar formalmente el derecho, y el segundo, al erigir esa concepción formal del derecho como la única válida. En un primer escalón, se reduce al identificar el derecho con lo formal, y en el segundo, se reduce al identificar ese derecho como bueno. IBARZABAL, Ignacio, El Maniaco del Unizono. Una Crítica Al Positivismo Por Su "Reduccionismo Epistemológico. Universidad de la Sabana. Bogotá: Editorial Dikaion, 2007, pp. 99-100.

47 Para Kelsen: "No puede situarse en duda, el postulado de la completa separación entre la jurisprudencia y la política no puede ser sinceramente puesto en tela de juicio". MELERO ALONSO, Eduardo. La dogmática jurídica es política. La importancia de las concepciones políticas en el trabajo de los juristas: Un acercamiento desde el derecho público. Madrid: Universidad Autónoma de Madrid. 2002, p. 36 
El estudio de las formulaciones jurídicas, puede enfocarse de manera aislada, como parte de un conjunto de normas, o como parte de un sistema normativo. Como formulaciones jurídicas aisladas se estudian los requisitos que debe cumplir una proposición para ser una formulación jurídica adecuada, es decir, lo concerniente a las cuestiones ontológicas y las relativas al carácter, contenido, condiciones de aplicación, autoridad, destinatario, ocasión de aplicación y sanción de las formulaciones jurídicas.

Como conjunto de formulaciones jurídicas relacionadas, se estudian las relaciones que deben existir entre las diferentes formulaciones jurídicas de determinado instituto, es decir, sus relaciones de no contradicción, coherencia, consistencia y plenitud. Se revisan las formulaciones jurídicas en un grado de abstracción y de relación superior al de las normas vistas desde manera individual, pero no desde el punto de vista de la totalidad del ordenamiento, a ello pertenece la tercera acepción.

Como conjunto o sistema normativo, se estudian las formulaciones jurídicas como una totalidad sistémica. Desde el punto de vista de las relaciones de no contradicción, coherencia, consistencia y plenitud del ordenamiento jurídico. La diferencia con lo signado en el párrafo anterior, es de nivel de abstracción y de puntos de referencia. Este nivel de abstracción conlleva a que los puntos de referencia sean mayores, por tanto, los resultados de lo que se estudia pueden variar. Así pues, lo que en un conjunto de formulaciones jurídicas relacionadas puede verse coherente, consistente, armónico, en un sistema jurídico puede no resultar de ese modo.

\section{Problemas del objeto de estudio}

Los problemas que puede presentar el objeto de estudio referido pueden verse desde tres perspectivas diferentes. Las cuales se relacionan directamente con el objeto de estudio. Estas perspectivas son: respecto de las normas individuales, como conjunto de formulaciones jurídicas y en cuanto al ordenamiento jurídico en su totalidad.

Acerca de las normas individuales se habla de problemas cuando las formulaciones jurídicas presentan inconvenientes en su estructura básica, bien sea desde el punto de vista del ser de la norma o de sus características principales. A los primeros, corresponden los problemas de existencia o validez de la norma. Es decir, de determinar si una norma existe o no, o es válida o inválida.

A los segundos, corresponde determinar problemas sintácticos o semánticos los cuales, en últimas, se pueden referir de forma general: al carácter, contenido, condiciones de aplicación, autoridad, destinatario, ocasión de aplicación, o sanción de las formulaciones jurídicas. En relación con el carácter, existen problemas cuando no se puede dilucidar si una determinada formulación jurídica, ordena, permite o prohíbe determinado estado de cosas; es decir, no está claro cuál es el operador deóntico que rige la formulación jurídica. Problemas de contenido en la formulación jurídica se dan cuando no está claro qué es lo que la formulación jurídica ordena, 
permite o prohíbe. Ya no se habla de que no está claro si la conducta es ordenada, prohibida o permitida, sino de qué es lo que está ordenado permitido o prohibido ${ }^{48}$. En cuanto a los problemas en las condiciones de aplicación, no está claro qué es lo que tiene que darse para que la norma se aplique, es decir, las condiciones que se ha de suplir para aplicar la norma.

En lo que refiere a la Autoridad, se presentan problemas de estudio cuando no se puede determinar fácilmente si quien emitió la disposición contaba con la competencia para ello, puede que se tenga que recaer en problemas referidos a la idoneidad jurídica de quien emitió la formulación jurídica. Los problemas referidos a los destinatarios, se dan cuando es difícil establecer a quiénes va dirigida la formulación jurídica, es decir, si a determinado grupo le es aplicable la formulación. En lo que refiere a los problemas de la ocasión de aplicación se refiere a problemas de la localización en el espacio y en el tiempo de las formulaciones jurídicas. Así pues, se puede revisar si una formulación jurídica es aplicable en determinado momento y en determinado lugar. En ocasiones no es claro, sobre todo para las formulaciones jurídicas que no son de orden nacional, aunque no se excluyen estas, si en determinados locales rigen ciertos preceptos o si comenzaron a regir, o si, fueron derogados o si la norma perdió su vigencia. Por último, podría decirse que pueden presentarse problemas respecto de la sanción jurídica cuando no resulta claro el establecer cuál es el alcance o la forma de la sanción aplicable a determinada conducta. Estas siete clases generales de problemas no son excluyentes entre ellos mismos. Puede presentarse problemas respecto al carácter y al contenido, o respecto a la sanción y las condiciones de aplicación. Inclusive, algunos problemas pueden subsumirse en varios tópicos.

La perspectiva del conjunto de normas jurídicas y las del sistema jurídico en su totalidad, obedecen a referentes aporéticos similares. Su principal diferenciación consiste en los diferentes niveles de abstracción y el punto de referencia que toman para ello; podría decirse, también, que se diferencian en la verticalidad y horizontalidad de las jerarquías normativas que se estudian. Los problemas que a esas perspectivas afectan, surgen cuando no se analiza específicamente las formulaciones jurídicas, sino, más bien, se ven como un conjunto que tiene como pretensión de supuesto, el ser racional, coherente, consistente y sin redundancias (tal vez la característica de racionalidad englobe a las demás). En este sentido se habla de problemas de vacíos, contradicciones (antinomias), incoherencias, inconsistencias, redundancias, reenvíos inadecuados, referidos a las relaciones que deben guardar las formulaciones jurídicas vistas como un conjunto de normas o como un sistema normativo. Se dice que hay vacíos cuando un caso que se considera que debería estar regulado jurídicamente no lo está, cuando para un problema jurídico no existe una clara solución legal. Existen contradicciones cuando dos o más formulaciones jurídicas señalan un punto de vista

48 En este punto, se trata, en su gran mayoría de problemas semánticos, sobre el contenido y el alance de las formulaciones jurídicas, luego resaltan problemas de ambigüedad, vaguedad, o indeterminación. 
o una toma de decisión diferente frente al mismo supuesto. Existen incoherencias e inconsistencias cuando una norma jurídica o unas normas jurídicas no se desprenden o siguen los lineamientos generales de otra norma o normas de superior jerarquía. Existen redundancias cuando dos normas jurídicas regulan de la misma forma el mismo caso. Y, existen reenvíos inadecuados, cuando existe error en la remisión jurídica de las normas.

La diferenciación establecida entre el estudio de un número plural de normas jurídicas y la revisión de sistema jurídico en cuanto totalidad, se justifica por cuanto, los referentes del segundo son más fijos y generales que los del primero, y requieren de un desarrollo más complejo que puede requerir un análisis de la verticalidad y horizontalidad de las formulaciones jurídicas. Lo cual, no sería adecuado equiparar con el análisis, por ejemplo, de la contradicción de dos normas pertenecientes a determinado instituto, pues los referentes, el grado de abstracción y el desarrollo son distintos $\mathrm{y}$, en principio, mucho más simples.

\section{Finalidad de la investigación jurídica}

La tarea de la investigación jurídica se ha denotado de diversas formas. Se ha entendido como: "describir las normas jurídico-positivas" las normas ${ }^{50}$, o en explicarlas ${ }^{51}$; o en deducir y ordenar sistemática y conceptualmente las formulaciones jurídicas ${ }^{52}$, o desde la función cognitivista y no cognitivista ${ }^{53}$,

49 “(...) la dogmática jurídica puede entenderse como el saber que trata de describir las normas jurídicopositivas”. MELERO ALONSO, Eduardo. La dogmática jurídica es política. La importancia de las concepciones políticas en el trabajo de los juristas: Un acercamiento desde el derecho público. Madrid: Universidad Autónoma de Madrid. 2002, p. 37

50 KARL LARENZ dice que la dogmática jurídica es aquella ciencia acerca del derecho que se ocupa de él ante todo bajo el aspecto del concepto normativo y, por ende, del sentido de las normas. Ibídem.

51 "La función principal que se le atribuye a este saber consiste en explicar el contenido de las normas jurídicas". Ibídem.

52 Según Kelsen la tarea de la investigación jurídica consiste "en deducir el contenido de las disposiciones jurídicas válidas con relación al sistema jurídico íntegro y, por último, ordenar conceptual y sistemáticamente, también con ese fin, el material jurídico, alivia al juez en la fundamentación de su decisión al suministrarle argumentos que son ampliamente aceptados como la respectiva doctrina dominante". KELSEN, Hans, Teoría General del Derecho y del Estado, México: Universidad Nacional Autónoma de México, 1995, p. 59

53 El modelo de Alchourrón y Bulygin distingue -en las prácticas teóricas de los dogmáticos del derecho- dos clases de actividades: las cognoscitivas, y las no cognoscitivas. Las primeras son actividades en las que se cumplen reglas de control racional e ínter-subjetivo de las proposiciones identificadoras de los dogmáticos. Las segundas, no pretenden informar sino expresar las normas que los legisladores y jueces de un sistema definido deben tener en cuenta para la fundamentación de sus decisiones prácticas. ALCHOURRÓN, Carlos, y BULYGIN, Eugenio, Introducción a la metodología de las ciencias jurídicas y sociales. Buenos Aires: Editorial Astrea, 1974, p, 6. 
desde el $i n-p u t^{54}$, desde el nivel empírico, analítico y normativo ${ }^{55}$, y no se espera que estas concepciones sean las únicas ${ }^{56}$.

Lo anterior, se puede aclarar de la siguiente forma. Con tal objeto de investigación y tales problemas, la finalidad es apenas presupuesta. Bajo tales presupuestos, fácilmente, se puede establecer la finalidad de la dogmática jurídica ${ }^{57}$. La finalidad de la dogmática jurídica ${ }^{58}$ o de la ciencia de la investigación en el derecho debe responder a la solución de los problemas signados, de manera directa o indirecta. De forma directa, se dice, cuando en la investigación jurídica de manera teórica se plantea la solución al problema, la cual puede ostentar dos enfoque: uno concreto

54 Según Luhmann, la dogmática jurídica, en su forma clásica, se caracterizaba por su orientación hacia el input del sistema, es decir, hacia el pasado, hacia las normas, y de ahí que a la dogmática se la hiciera cumplir, fundamentalmente, funciones clasificatorias (los conceptos proporcionaban reglas para estandarizar y clasificar casos sometidos a decisión). Esta orientación venía reforzada por una concepción de la justicia como igualdad abstracta (la justicia consistiría en decidir de manera igual casos -formalmente- iguales) concepción que, a su vez, servía para valorar positivamente el proceso de autonomización (diferenciación) del sistema jurídico. Cfr. ATIENZA, Manuel. El Futuro de la Dogmática Jurídica, Critica de Libros, Madrid: El Basilisco, 1980, p. 64

55 En la dimensión analítica de lo que se trata es de la consideración sistemático conceptual del derecho valido. El espectro de las tareas se extiende desde el análisis de los conceptos fundamentales, pasando por la construcción jurídica, hasta la estructura del sistema jurídico, y de la fundamentación sobre la base de los derechos fundamentales. En una dimensión empírica de la dogmática jurídica se puede hablar en un doble significado: primero, con relación al conocimiento del derecho positivamente válido y, segundo, con relación a la utilización de las premisas empíricas en la argumentación jurídica. El conocimiento del derecho positivamente válido es tarea de la dimensión empírica. El material dotado de autoridad obtenible de la dimensión empírica no basta, en todos los casos más o menos problemáticos, para fundamentar vinculantemente el juicio jurídico de deber ser. Ello hace necesario recurrir a valoraciones adicionales, y, así, a la dimensión normativa. Presupuesto de racionalidad de toda ciencia es la calidad conceptual, la no contradicción y la coherencia. ALEXY, Robert, Teoría de los derechos fundamentales, Madrid: Centro de Estudios Políticos y Constitucionales, Impreso en Solana e hijos, A. G., S. A., 2002, pp. 30-34

56 Por ejemplo: "El problema del cientificismo de la teoría del derecho se plantea, en nuestros días, un tanto diferente. Si se concibe a la teoría del derecho en sus estructuras complejas que corresponden a las del fenómeno jurídico: sociológicas, axiológicas, lógico normativas y epistémicas, no será suficiente examinar el problema únicamente con la bipolaridad ius-naturalismo-ius-positivismo. Petev, Valentín. Metodología y Ciencia Jurídica en el Umbral Del Siglo XXI. Traducción de Luis Villar Borda. Bogotá: Universidad Externado de Colombia, 1996, p. 91

57 "La dogmática jurídica persigue de todos modos una actualización semejante de las disposiciones legales, que pertenecen a su objeto de investigación. Lo hace, en verdad, la mayoría de las veces. A través de esto no sólo descarga al juez, sino al mismo tiempo lo limita, puesto que lo lleva a apoyarse exclusivamente en construcciones dogmáticas y a exteriorizar sus argumentos en toda dimensión." Petev, Valentín. Metodología y Ciencia Jurídica en el Umbral Del Siglo XXI. Traducción de Luis Villar Borda. Bogotá: Universidad Externado de Colombia, 1996. p, 59.

58 "El rasgo característico de la metodología tradicionalista era una cierta estabilidad y permanencia en cuanto a los objetivos que perseguía y los postulados que formulaba. El mayor deseo fue no solo alcanzar una aproximación aclaratoria de los problemas que plantea la interpretación y la aplicación del derecho, sino también y, sobre todo, elaborar un instrumento, una técnica segura que garantice soluciones correctas y justas." Ibídem. 
y otro general. De forma indirecta, se dice cuando se toma la solución dada en la manera directa para tratar de corregir el problema.

La manera directa concreta puede darse en dos enfoques diferentes que responden a la clase de problemas que se aborden. Así pues, en primer lugar, se alude a la solución de los problemas de las normas vistas desde una concepción aislada. Acá, se trata de enfocar la investigación en un doble sentido. En el primero, se tiene como finalidad determinar si una norma existe o no, si es válida o inválida. En el segundo sentido, la finalidad consiste en determinar el carácter, contenido, condiciones de aplicación y demás, de las formulaciones jurídicas. En cierto modo puede decirse que este sentido tiene como finalidad describir las formulaciones jurídicas.

En un segundo enfoque, se asume el estudio de tales formulaciones desde el punto de vista de la sistematización total o parcial del ordenamiento jurídico ${ }^{59}$. Lo que importa como finalidad de la investigación jurídica es reformular las normas o conjunto de normas aporéticas para que respondan a los criterios de racionalidad del ordenamiento como un todo o como parte de él.

Dentro del primer y segundo enfoque reseñado, puede insertarse un tercer enfoque, un grado que puede verse como un punto intermedio entre ellos dos. Una comunicación para liberar la tensión dada entre tales enfoques. Así pues, puede referirse a un enfoque intermedio que no refiere a la solución de problemas precisos o concretos sobre las formulaciones jurídicas ni a la solución de los problemas de racionalidad de una pluralidad de normas jurídicas. En este campo se analizan conceptos jurídicos trascendentes, los cuales responden a un nivel de abstracción mayor al de la manera directa en su enfoque concreto pero que no lleva al grado de abstracción del segundo enfoque. No se quiere determinar el carácter, sentido y alcance de las formulaciones jurídicas o hacer coherentes y consistentes tales, ni pretender una amplia racionalidad de las formulaciones jurídicas, sino que el trabajo se enfoca en emprender un análisis de los conceptos jurídicos (que ostentan un grado de abstracción que fundamenta, encubre o relaciona diferentes normas jurídicas). En este estadio se revisan conceptos tales como el de los derechos subjetivos, la disponibilidad de derechos, entre otros.

La forma indirecta de la investigación jurídica tiene como finalidad dar parámetros de racionalidad al juez y al legislador ${ }^{60}$. Es, en otras palabras, una función

59 Se ha considerado siempre el derecho tiene algún tipo de orden sistemático, pues la sistematización (u ordenación) de las disposiciones jurídicas es tradicionalmente considerada como importante que compete tanto al legislador, como al científico". ALCHOURRÓN, Carlos y BULYGIN, Eugenio, Introducción a la metodología de las ciencias jurídicas y sociales. Buenos Aires: Editorial Astrea, 1974. p, 22.

60 Cfr. PETEV, Valentín. Metodología y Ciencia Jurídica en el Umbral Del Siglo XXI. Traducción de Luis Villar Borda. Bogotá: Universidad Externado de Colombia, 1996. p, 96-97. ATIENZA, Manuel, y FERRAJOLI, Luigi. Jurisdicción y Argumentación en el Estado Constitucional. México: Universidad Nacional Autónoma de México. 2005. p. 21 
normativa, no cognitiva ${ }^{61}$. Pues su objetivo primordial es dar enunciados preceptivos de deber ser, señalar los parámetros mediante los cuales el ente judicial o legislativo debe actuar. Es no cognitiva, esta función por cuanto no se trata tanto de resolver problemas cognitivos en las formulaciones jurídicas, sino que se trata, más bien, de utilizar el resultado de los procesos cognitivos. Mediante esta función se libera y ata al juez y al legislador. Libera, por cuanto, el objetivo de esta función puede verse como una forma de descargar las labores justificadoras del juez y del legislador; ata, por cuanto, la actividad judicial o legislativa debe ceñirse a los parámetros entregados por la dogmática jurídica.

No puede negarse la íntima relación que existe entre la función directa y la indirecta. Tanto así, que es apenas lógico pensar que la indirecta presupone la directa. Para que pueda obrar la indirecta se necesita la directa. No obstante, al parecer, la directa no presupone la indirecta, pues, en el tiempo es la primera. Empero, podría pensarse que existe una relación circular entre ellas. Podría decirse que la primera presupone la segunda en una entidad defectuosa. Una función directa se da cuando pretéritamente ha existido una indirecta que no ha sido adecuada, lo cual, da lugar a la función circular. Lo cual, se exceptúa cuando no ha existido ninguna función directa.

\section{Juicios de valor en la investigación jurídica}

Una de las cuestiones más significativas y debatidas en torno a la investigación jurídica es la eliminación de los juicios de valor. Tal eliminación se ha enfocado, específicamente, en dos vertientes. La primera, refiere a la eliminación de los juicios de valor del objeto de la investigación jurídica, y, la segunda, refiere a la eliminación de los juicios de valor en la actitud del investigador. Como es notorio la una recae sobre el objeto y la otra sobre el sujeto ${ }^{62}$.

En lo que refiere a la eliminación de los juicios de valor en el objeto de la investigación jurídica, pueden verse dos versiones: una extremista y otra moderada. Según la extremista se debe eliminar cualquier juicio de valor del objeto de estudio. Bajo esta óptica "derecho y justicia son conceptos diferentes". "Liberar el concepto del derecho de la idea de la justicia" ${ }^{\prime}$, resulta ser una prioridad. Empero, se cae

61 ALEXY, Robert, Teoría de los derechos fundamentales, Madrid: Centro de Estudios Políticos y Constitucionales, Impreso en Solana e hijos, A.G., S.A., 2002. p. 34

62 Los juicios de valor no sólo pueden horadar el objeto y la actitud del investigador, sino también, pueden verse en el método que se utiliza para llevar a cabo la investigación. De ello se desprende que la mejor forma de pretender la objetividad no se encuentra tan sólo en el objeto o la actitud, sino en métodos que de cierta forma garanticen una pretensión de objetividad. El objeto y la actitud del intérprete adecuado para efectuar investigación se situaría en ciernes si el método no obrara en un sentido similar. Si se utilizara un método que no garantizara la pretensión de objetividad en los conocimientos que desea adquirir.

63 KELSEN, Hans, Teoría General del Derecho y del Estado, México: Universidad Nacional Autónoma de México, 1995, p, 6. 
en un error al querer esto. Ahí se encuentra la virtud de la concepción moderada. De cierta forma siempre van a existir juicios de valor en el objeto de estudio. Por tanto, se obra mal cuando se ostenta una concepción extremista, según la cual, se quiera desligar cualquier valor del objeto de estudio. Si bien, no siempre serán los clásicos valores morales (alegados por el iusnaturalismo) sí existen intrínsecamente al objeto de estudio valores propios de un ordenamiento jurídico cualquiera. Es así, que se habla, en la versión moderada, de valores tales c omo el orden, la seguridad, la estabilidad y la democracia, entre otros ${ }^{64}$.

Los valores atrás referidos son valores preestablecidos en el ordenamiento, los cuales no pueden ser obviados por cuanto hacen parte del objeto de estudio, son intrínsecos a él. La versión moderada no sólo considera que el objeto de estudio ostenta ciertos valores intrínsecos a él, sino que alega por la eliminación de los demás valores. Aprovecha de forma más limpia el estudio del objeto la versión moderada, toda vez que es consciente de los valores que existen, por tanto, descarta los que no sean propios al objeto. Sería fútil considerar que el establecimiento de ciertos postulados fundantes no requirió juicios de valor (acá no se hace alusión a las consideraciones políticas de la producción legislativa, sino, más bien, a los valores intrínsecos al ordenamiento jurídico). La principal diferencia entre la versión extrema y la moderada viene a ser la conciencia sobre la existencia de los valores del ordenamiento y su aceptación como parte del objeto de estudio del moderado.

Bajo la versión extrema o moderada, se debe estudiar el derecho que es y no el que debiera $\operatorname{ser}^{65}$. Con la anterior proposición se infiere la existencia de dos clases de derechos, uno real y otro ideal. Bajo esta óptica debe estudiarse el derecho existente, y, despreciarse, como objeto de estudio, el derecho ideal. El derecho existente no debe ser desplazado por el derecho que se espera que exista o aquel derecho que promueva determinados valores esperados. Se considera derecho desde esta óptica, como objeto de estudio, las disposiciones que hayan sido dictadas de cierta forma mediante antedicho procedimiento y que no contravengan normas de índole

64 Esta imagen ideal no impide, sin embargo, que la dogmática pueda realizar valoraciones. Ni que la dogmática se defina como un conocimiento valorativo, axiológico. Los valores que están implicados en la dogmática no son, sin embargo, los valores, ideas y concepciones personales de cada jurista, sino que son los valores que se desprenden del ordenamiento jurídico en su conjunto. De este modo, el jurista debe limitarse a aplicar las pautas de valoración que establece el ordenamiento jurídico. MELERO ALONSO, Eduardo. La dogmática jurídica es política. La importancia de las concepciones políticas en el trabajo de los juristas: Un acercamiento desde el derecho público. Madrid: Universidad Autónoma de Madrid. 2002, p, 9-11

65 "La teoría pura se acerca al método científico positivista al examinar su objeto, el derecho, como un hecho, es decir, como un dato positivo y concebible". "La influencia del positivismo y del neopositivismo se manifiesta en el supuesto conforme al cual el conocimiento del derecho debe ser puramente descriptivo y no valorativo". Petev, Valentín. Metodología y Ciencia Jurídica en el Umbral Del Siglo XXI. Traducción de Luis Villar Borda. Bogotá: Universidad Externado de Colombia, 1996, pp. 96-97 
superior. Para la determinación del derecho que existe se toman en cuenta criterios de validez. La existencia del derecho se reduce a la validez. En la mayoría de las ocasiones y, pese a los problemas que puede presentar ello, se justifica la validez de las normas del ordenamiento jurídico mediante alusiones a normas fundantes o reglas de reconocimiento o criterios circulares que intentan demostrar la validez de los elementos que componen el ordenamiento jurídico.

Por su parte, la eliminación de los juicios de valor del sujeto que investiga es un asunto muy debatido. Este escrito no pretende abordar de fondo tal tema. Simplemente, pretende decir que pueden existir dos posiciones extremistas y opuestas entre sí: una que alega por la eliminación total de los juicios de valor, $y$, otra que alega por la imposibilidad de sustraer la subjetividad de la investigación, de esta última pueden existir varias versiones.

Para abreviar las cosas se dice: es muy complicada la postura según la cual se pueda eliminar del actuar humano cualquier juicio de subjetividad. Los embates contras los idola de Bacon no son del todo posibles. Los hombres, en frecuentes casos, ostentan mayor motivo de actuación en lo sensible que en lo racional. La subjetividad, en la mayoría de las veces o en un alto porcentaje de ellas, engloba la racionalidad. Ello, en materia jurídica, lo ha mostrado muy bien la Critical Legal Studies (CLS). Por tanto, es muy difícil o imposible concebir una actitud totalmente anti-subjetiva, avalorativa. También se dice que es muy complicada una posición según la cual los juicios de subjetividad rijan de manera mayoritaria el actuar del investigador. Muy difícilmente existe rigurosidad o pretensión de objetividad en el proceso investigativo y en el resultado de éste, si las subjetividades rigen a su amaño la labor del jurista. Luego, queda como opción tomar una posición intermedia, según la cual se reconozca la subjetividad del individuo pero exista la pretensión de su control y la intención de que su utilización consciente ayude a controlarla; de cierta forma se considera que éste es el mejor campo para abordar la tarea del investigador jurídico.

\section{Reflexiones finales}

El derecho puede verse, de forma general, desde tres perspectivas. Las cuales, a su vez, sirven para deslindar el campo de estudio de diversas ciencias. Así pues, puede fácilmente establecerse que el objeto de estudio de la investigación jurídica es diferente al objeto de estudio de la filosofía política y de la sociología jurídica.

La anterior delimitación, además de hacer más comprensibles los elementos que giran en torno a la investigación jurídica, se presenta como una concepción diversa a las corrientes contemporáneas que tratan de una u otra forma por la reivindicación del saber totalizador. En donde las investigaciones se acentúan en la legitimidad del derecho a través de procedimientos discursivos racionales, o mediante la concepción del derecho como integridad, o mediante el análisis de las consecuencias, o de situaciones referentes a la eficacia del derecho. 
No es que se esté en contra de la interdisciplinariedad o de la transdisciplinariedad. Se trata, más bien, de una postura que ve los elementos desde dentro de la misma ciencia. Es decir, la investigación jurídica ve la legitimidad y la eficacia no como situaciones aisladas a las formulaciones jurídicas que haya que integrar sino como elementos que hacen parte de la validez en cuanto estén inmersos en ella. No desde el punto de revisar las formulaciones jurídicas junto con su acoplamiento con la justicia o junto con su cumplimiento, sino ver la legitimidad y la eficacia en la medida en la que estén representadas en las formulaciones jurídicas, en la medida en que participen de la noción de validez. Con lo cual, se marca una de las diferencias de la concepción acá defendida, con la de la Teoría Pura -pues, el rechazo metafísico, sociológico o de subjetividad, característico de la Teoría Pura, en este escrito no son tan extremos, pues se ven tales cuestiones como una participación interna, en distintas medidas, en la noción de validez-.

Así pues, la mejor forma de entender la investigación jurídica es la de concebirla desde el estudio de las formulaciones jurídicas. A ello, se considera importante, agregar dos observaciones finales. La una, refiere al inacabamiento de la tarea del jurista, y, la otra, refiere a una advertencia sobre una situación que se debe evitar (vitanda) en la investigación jurídica.

La tarea del jurista pese a que es científica, es inacabada, es constante. No puede pensarse que llega a un estadio en el cual se entiende completa. Pese a los adelantos en las concepciones de lo jurídico y de la labor investigativa no se llegará a completar ésta, el objeto del derecho y su tarea son inconclusos. No tienen productos como las reglas de la matemática o la física inmutables o inalterables. Pues, el objeto del derecho que hace que no pueda ser una ciencia exacta es lo mismo que hace que tal tarea no pueda acabarse en algún momento. Pese a que han cambiado, por ejemplo, las clásicas formas de aplicar la ley por test con metodologías más elaboradas, no puede decirse que éstos, a pesar de haber transcurrido milenios, puedan ser el perfeccionamiento de la aplicación del derecho. Cuando se trató de defender que la tarea de la investigación jurídica podría ser considerada como científica, se refirió una especie de racionalidad limitada en la investigación jurídica, y se estableció que la exactitud de la investigación jurídica demandaría un híper racionalismo. Es, específicamente, la falta de la exactitud en la investigación jurídica y el racionalismo limitado sobre el objeto de estudio de lo jurídico que puede hablarse de una tarea en ascenso pero inacabada.

La característica del inacabamiento de la investigación jurídica, necesita verse con otra advertencia. Pues, en algunos casos puede verse que la investigación jurídica hace lo que trata de evitar. Se dice que la investigación jurídica, en últimas, trata de describir o determinar el sentido del derecho positivo, de obtener criterios de racionalidad que garanticen cierto nivel de estabilidad, no obstante, podría pensarse que en algunas ocasiones el remedio perjudica lo que quiere sanar. Pues, existen autores que afirman, que la investigación jurídica acaba por deformar el derecho 
positivo so pretexto de aclararlo. Algunas formulaciones jurídicas podrían parecer adecuadas hasta tanto la investigación jurídica no la horada con múltiples aporías.

Para evitar aquella concepción que "la dogmática acrecienta, pues, el grado de incerteza del sistema jurídico" y que conlleva con ello la incompatibilidad con la finalidad misma de la dogmática, se podría pensar, que se ha de eliminar la tesis según la cual la finalidad de la investigación jurídica es estabilizadora y de control racional, o la tesis según la cual las formulaciones jurídicas o las relaciones de ellas, pueden fácilmente problematizarse. No obstante, no se considera fácilmente posible lograr tal cosa. No puede eliminarse el postulado según el cual la función de la dogmática es estabilizadora, creadora de criterios de control racional, su eliminación conllevaría a la negación de la misma tarea investigativa. Por el objeto de estudio escogido por la investigación jurídica, es necesario, es un presupuesto lógico trascendental, que la finalidad de la labor investigativa sea la planteada. No existe posibilidad por fuera de ella, ni campo diferente. El objeto de estudio y los problemas que presenta no hacen posible variar tal finalidad. Tampoco puede abolirse el postulado según el cual las formulaciones jurídicas o las relaciones lógicas pueden fácilmente problematizarse, la jurisprudencia analítica y las lógicas modernas han recalcado lo endeble del lenguaje y de las relaciones de las normas.

Ante esto, se piensa que la mejor forma de la solución de tal aporía consiste en pensar que la investigación jurídica debe darse en un estadio temporalmente posterior al de la consolidación del problema. Es decir, no ha de ser bien visto en la investigación jurídica el hecho de deformar las formulaciones jurídicas para luego estudiarlas, es como si un médico creara una enfermedad para luego intentar curarla. La ideología estabilizadora, el respeto a las formulaciones jurídicas, los dogmas de la investigación jurídica, hacen necesario que la investigación jurídica se dé en un momento posterior a la consolidación de la aporía.

Si esto no ocurre así, sí se desdibujan, por ejemplo, los límites de las formulaciones jurídicas, para luego estudiarlas, ello se debería a una actitud inadecuada del investigador, y no a un problema de la dogmática jurídica. O, en últimas a un riesgo inevitable por la tarea que se efectúa.

\section{REFERENCIAS}

Alchourrón, Carlos y Bulygin, Eugenio. Introducción a la metodología de las ciencias jurídicas y sociales. Editorial Astrea. Buenos Aires. 1974.

ALEXY, Robert, Teoría de los derechos fundamentales. Madrid: Centro de Estudios Políticos y Constitucionales, Impreso en Solana e hijos, A.G., S.A., 2002.

Alexy, Robert. El concepto y la validez del derecho. Barcelona: Gedisa. 2004.

Atencia, José María, Positivismo y Neopositivismo, Revista Universidad de Málaga, S.F. 
Atienza, Manuel; Ferrajoli, Luigi. Jurisdicción y Argumentación en el Estado Constitucional. México: Universidad Nacional Autónoma de México. 2005.

Atienza, Manuel. El Futuro de la Dogmática Jurídica, Critica de Libros, Madrid: El Basilisco, 1980.

Atienza, Manuel. El Futuro de la Dogmatica Jurídica. Critica de Libros. El Basilisco, Madrid. 1980.

Bobbio, Norberto. Teoría general del derecho. Santa Fe de Bogotá: Editorial Temis. 1997.

Díez, José y Moulines, Ulises. Fundamentos de Filosofía de la Ciencia, Barcelona: Ariel, 1997.

Friedrich, Karl von et al., La ciencia del derecho, Buenos Aires: Editorial Losada: 1949

Hessen, Johannes, Teoría del Conocimiento, Editorial Tomo, México, 2003.

Ibarzábal, Ignacio, El Maniaco del Unizono. Una Crítica al Positivismo por su Reduccionismo Epistemológico. Universidad de la Sabana. Bogotá: Editorial Dikaion, 2007.

Kantorowicz, Hermann. La lucha por la ciencia del derecho, trad. de Werner Goldschmidt, en Savigny.

Kelsen, Hans, Teoría General del Derecho y del Estado, México: Universidad Nacional Autónoma de México, 1995.

Lariguet, Guillermo. La Reconstrucción de las 'Teorías Dogmático-Jurídicas' como Cálculos Interpretados. Una exploración conceptual sobre su plausibilidad filosófica. Recuperado el 5 de octubre de 2010, de la dirección Web: http://www.aafd. org.ar/archivos/15_jornada_Lariguet.pdf.

Mejía Quintana, Óscar, La problemática iusfilosófica de la obediencia al derecho y la justificación constitucional de la desobediencia civil. Bogotá: Universidad Nacional de Colombia, 2001.

Mejía Quintana, Óscar. Elementos para una reconstrucción del estatuto epistemológico de la filosofía del derecho, en Humanitas (No. 33), Nuevo León: Centro de Estudios Humanísticos, Universidad Autónoma de Nuevo León, 2006

Melero Alonso, Eduardo. La dogmática jurídica es política. La importancia de las concepciones politicas en el trabajo de los juristas: Un acercamiento desde el derecho público. Madrid: Universidad Autónoma de Madrid.

Nagel, Ernest. La estructura de las ciencias, Buenos Aires: Paidós, 1968.

Petev, Valentín. Metodología y Ciencia Jurídica en el Umbral Del Siglo XXI. Traducción de Luis Villar Borda. Bogotá: Universidad Externado de Colombia, 1996. Santiago Nino, Carlos. Consideraciones sobre la Dogmática Jurídica. México, Universidad Autónoma De México. 1974. 
Schreiber, Rupert. Lógica del Derecho. Distribuciones Fontamara. México 1999. Tomás De Aquino. Suma Teológica, I, II, cuestión 57.

Viehweg, Theodor. Tópica y jurisprudencia, traducción de Díez-Picazo, Luis España: Taurus. 1964.

Vigo, Rodolfo Luis, El Iusnaturalismo actual. Biblioteca de ética, filosofía del derecho y política. México. 2003. 